\title{
Short-Term Microclimate Variation and Leaf Litter-Derived Soil Organic Carbon Formation Under Different Coffee and Cocoa Cropping Systems
}

\author{
Erwin Prastowo $^{1 *)}$ and Laily Mukaromah ${ }^{2)}$ \\ ${ }^{1}$ Indonesian Coffee and Cocoa Research Institute, J1. PB. Sudirman No. 90, Jember, Indonesia \\ ${ }^{2)}$ Research Center for Plant Conservation and Botanic Gardens, Indonesian Institute of Sciences (LIPI), Indonesia \\ *)Corresponding author : eprastowo@iccri.net \\ Recieved : 14 May 2020 / Accepted : 22 June 2020
}

\begin{abstract}
Litter plays a crucial role in the formation of soil organic carbon (SOC), and potentially affects different pools in the context of soil carbon cycle. To improve knowledge and understanding with respect to the dynamics of carbon in coffee and cocoa cropping systems, there is a need to develop a mechanistic model to explain the formation of carbon especially in different background of soil, climate and agronomic management. Short-term observation was performed in different cropping systems, i.e. coffee (Coff) and cocoa (CoL) with lamtoro (Leucaena sp.) shade trees, and cocoa with oil palm (Elaeis guineensis) shade trees $(\mathrm{CoP})$, and teak (Tectona grandis) conservation area, to investigate the quantitative amount of leaf litter-derived carbon. Additionally, to improve the understanding with respect to the formation of soil organic carbon, a simple model is developed by employing organic carbon storage coefficient (hi) as parameter to validate the observation data from Coff and CoL plots. Leaf litter is collected daily with concomitant microclimate records, i.e. air temperature, relative humidity, light intensity, and soil temperature. Composite soil and leaf samples are collected for organic carbon, soil moisture content, and leaf relative water content (RWC), for laboratory identification. Analysis of data suggests the presence of cropping system effect, i.e. shading condition and agronomical practices such as pruning, to microclimate variations except for soil temperature. Furthermore, cropping systems do not significantly influence soil moisture content, amount of organic carbon, and RWC. With higher model efficiency (EF), the simulated model fits better for CoL, EF 0.95, than Coff, EF 0.58. Model simulation, with both $h i$ values are 0.017 and 0.014 in Coff and CoL, reveals a possibly cropping system specific curve pattern. A faster SOC formation in Coff plot has suggested a crucial role the amount of leaf litter to support with continuous carbon supply. The simulation implies the presence of soil related-maximum point limiting carbon storage capacity.
\end{abstract}

Keywords: Coffee, cocoa, leaf litter, soil organic carbon

\section{INTRODUCTION}

Recent reports have revealed an important contribution of litter to organic carbon dynamics in the soil, for instance to carbon accumulation (Novara et al., 2015; Paul, 2016; Cao et al., 2020), and soil microbial activity (Kögel-
Knabner, 2017; Chen et al., 2020). Carbon stored in the soil, as a main reservoir for terrestrial carbon, provide a potential feedback as a response to global warming ( $\mathrm{Lal}, 2011)$. Consequently, soil carbon sequestration is highly important since a considerable change in this pool would potentially affect the global 
carbon cycle. Litter contribution may be related to a continuous supply of new carbon and maintain its level to a steady-state condition. Though a considerable litter-derived carbon is mostly existed in the top soil, yet a potential indirect transport to subsoil such as through dissolved organic carbon down, and bioturbation, may be present (Rumpel \& Kögel-Knabner, 2011), giving rise to a potential subsoil organic carbon enrichment as an additional option with respect to terrestrial carbon sequestration.

Additionally, fresh plant litter provides soil microbes with energy for their activities. During microbial decomposition, amount and chemical quality of litter may limit the formation of SOC (Manzoni et al., 2012). As both amount and chemical composition of organic carbon is likely crop-type dependent, therefore a considerable effect of cropping system to the formation of SOC may be expected. Furthermore, a high quality of plant litter with high carbon mineralization rates tends to promote SOC accumulation (Córdova et al., 2018).

The agroforestry cropping system in coffee and cocoa has provided a specific shade condition in which the improved microclimate environment, i.e. $\mathrm{RH}$, may help to reduce the impacts from full sunlight exposure such crop drought stress. As an additional to their positive effect to coffee and cocoa farming systems (Evizal et al., 2009; Yulianti et al., 2018), the shade crops may contribute to an extra plantderived organic carbon such as leaf and pruned litter into the soil. The shade crop used to combine with coffee and cocoa may locally vary depending on economical decision to deal with the land productivity. Therefore, there is a potential specific condition with respect to the formation of SOC as a result of crop-type dependent of amount and quality of litter.
The estimate of carbon stocks provided by coffee and cocoa agroforestry systems has been reported, for instance Ehrenbergerová et al., (2016), and Monroe et al., (2016), to evaluate their potential soil carbon sequestration in compare to different cropping systems. Similarly, most of paper reports the absolute amount of carbon stored in the crop systems by taking into account either soil or trees as carbon reservoirs without any further information related to the dynamic processes responsible for current condition.

Therefore, to do so, this paper will discuss a simple mathematical model following a short-term field observation in coffee and cocoa farms subject to the same climatic condition, and soil type. Additionally, soil and crop parameters, i.e. SOC, soil moisture, and RWC, are also discussed in response to cropping systems with diurnal microclimate variations records to support the analysis.

\section{MATERIALS AND METHODS}

\section{Field Site}

Field investigation was performed in Kaliwining Experimental Station, Indonesian Coffee and Cocoa Research Institute in Jember, East Java, Indonesia, during dry season July 2019. The moderate development stage of Inceptisol at about $60 \mathrm{~m}$ asl. topographically plain of area (Prastowo et al., 2020), provide a suitable soil fertility condition to coffee and cocoa growth. Three different plots posing slightly different cropping systems were observed. They are coffee (Coff) and cocoa (CoL) with lamtoro (Leucaena sp.) shade trees, and cocoa with oil palm (Elaeis guineensis) shade trees (CoP). All these sampling crops were selected randomly to represent the observation area. Coff plot with 2013 planting year of Robusta coffee has a density about 1600 trees per ha, 
while for CoP and CoL plots with both 2015 and 2014 planting years of cocoa as main crops have a population of about 1100 trees/ha. An additional teak (Tectona grandis) conservation area was also evaluated with respect to its total organic carbon content.

During field observation, regular agronomic practices were operated following the experimental station's cocoa cultivation guidelines. All field operational related to cocoa agronomy that taking place during the observation was recorded to support the data evaluation.
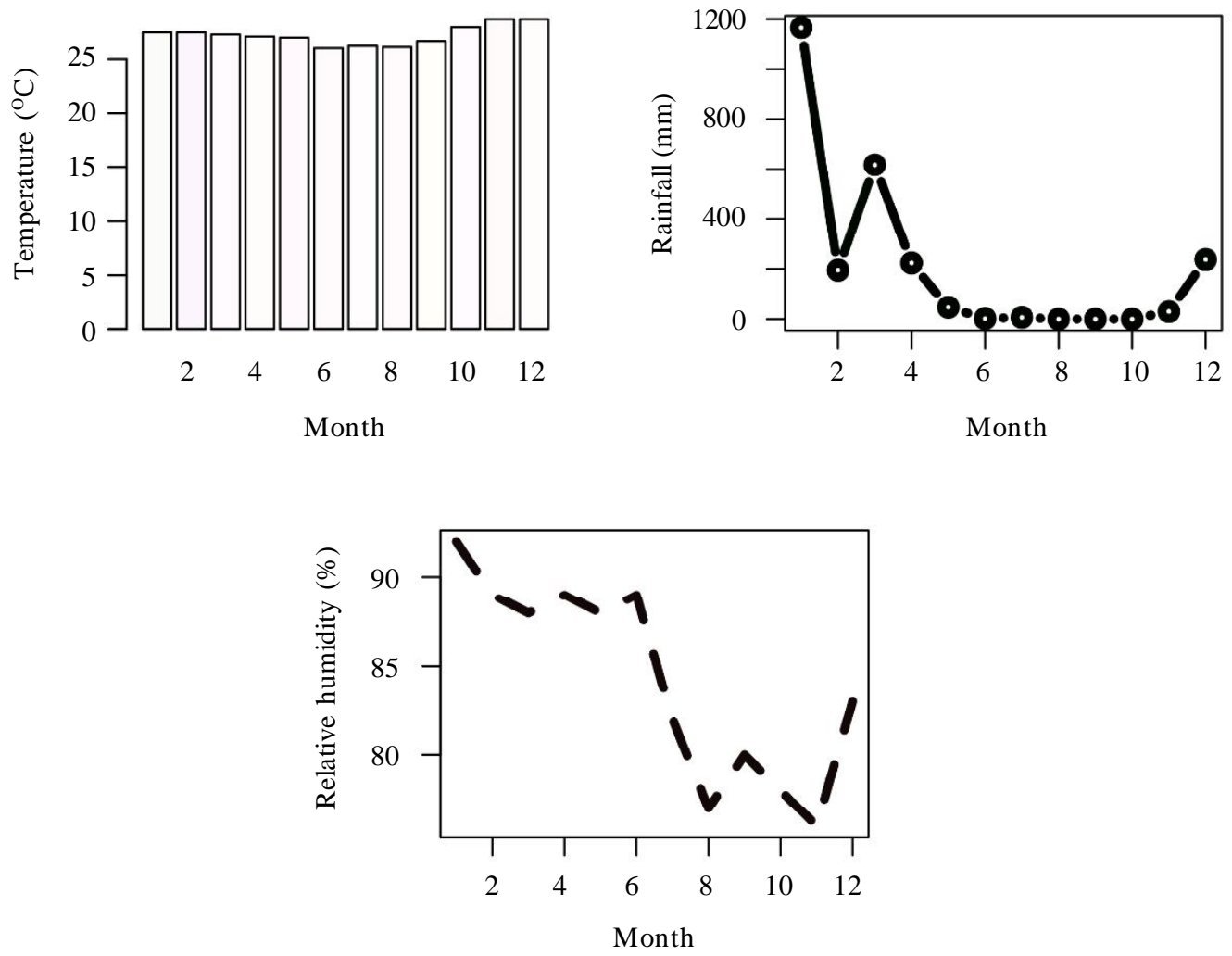

Figure 1. Air temperature $\left({ }^{\circ} \mathrm{C}\right)$, rainfall $(\mathrm{mm})$ and relative humidity $(\%)$ in Kaliwining Experimental
In 2019, the Kaliwining Experimental Station was subjected to seven dry months with less than $60 \mathrm{~mm}$ (Figure 1). Additionally, data record showed three consecutive months where no rainfall occurred from August to October. When fieldwork was being performed in July a less than $10 \mathrm{~mm} /$ month of rainfall was recorded. The average temperature was around $27^{\circ} \mathrm{C}$ with relative humidity around $84 \%$, and showed to decrease down to $76 \%$ during dry periods (Figure 1).

\footnotetext{
Station during the study in 2019
} 


\section{Fieldworks}

To estimate the amount of carbon input per day in each cropping system, leaf litter was collected from randomly selected three trees per observation plot in a daily basis. The old yellowish leaves from observed trees were attached to the branches by a string so later they will keep hanging when dropped (Erwiyono et al., 2012). The number of daily leaf drop varied, i.e. 2.31, 3.08, and 2.76 leaves/day/tree for CoL, Coff, and CoP. The hanging leaves were collected and measured out for their both fresh and dry weight. This work was regularly performed for 10 days. Additionally, the composite sample of leaf drop was prepared for organic carbon content in the laboratory.

The ring samples were also collected for bulk density (BD) measurement. A known volume and weight of rings were inserted down to circa $0-20 \mathrm{~cm}$ depth of soil surface. Both top and bottom of sample rings were levelled by a small knife, and covered by a plastic stopper immediately. The rings were then transported to the laboratory for both fresh and oven-dry soil weight.

A composite top soil samples were taken from the observation tree's circle by a soil sampler probe, and replicated three times. Four point of samples from four different direction about $50 \mathrm{~cm}$ distance from centre of tree were taken in every sample trees. A soil sampling was performed once during the course of field investigation to evaluate the effect of long-term cropping system, e.g. organic litter input, and agronomic practices to SOC formation.

Fresh leaf samples were taken for organic carbon content, and relative water content (RWC) measurement. The organization of leaf sampling adopted the field guidance provided for nutrient analysis (Prastowo et al., 2019).
Climate of microenvironment at the immediate vicinity of sample trees just below the canopy were observed regularly at daily basis i.e. air temperature, humidity, light intensity, and soil temperature, for 14 days. They were recorded by handheld instruments three times per day at 07.00, 12.00, and 17.00 Western Indonesian Time. Air temperature, relative humidity, and light intensity were measured with triplication both at just the same level, and at $100 \mathrm{~cm}$ above the ground while soil temperature was recorded by inserting the instrumen's sensor probe at about $10 \mathrm{~cm}$ below the soil surface. To simplify the presentation, climate data recorded were averaged, and plotted along the horizontal axis to expose their short-term diurnal fluctuations (Figure 2).

\section{Laboratory analysis}

Fresh leaf and soil samples collected in the morning were transported to the laboratory as soon as they were ready for further preparation including oven-drying, and chemical measurement. The soil moisture and RWC were measured by oven-dry samples at both $105^{\circ} \mathrm{C}$ for 24 hours. The total organic carbon for both soil (Figure 4), and leaf samples were prepared by a Walkley and Black method, and followed by a spectrophotometric reading. The organic carbon content of leaf samples obtained from different cropping systems is used for carbon model simulation, will be discussed in the next section.

\section{Statistical analysis}

Both one way and two analysis of variance were used to analyse the experiment data. The first technique was performed to evaluate the effect of cropping systems to SOC (Figure 4). A single factor allowed for three different cropping system, i.e. Coff, CoL, $\mathrm{CoP}$, and Teak, to analyse. Furthermore, two 
analysis of variance was also performed to deal with microclimate data, i.e. air temperature, relative humidity, light intensity, and soil temperature. The first factor is cropping systems as stated above only now the Teak's measurement was not determined. While the second factor is the number of observation day. The analysis also took into account the interaction between the two factors (Table 1). Additionally, both analysis of variance was followed by a multiple comparison Tukey's posthoc test at level of significant $(\alpha) 0.05$ to explore differences between multiple group's means.

\section{SOC formation model formulation}

To improve the understanding in view of cropping system effect to the dynamics of carbon input and the formation of soil organic carbon, a simple mathematical model was developed using an ordinary differential equation system. The formation of top soil carbon in the steady state condition, where no leaching is present, is the function of sequestration rate, and loss of carbon through microbial decomposition. Once plant derived of fresh organic residues such as leaf litter deposited, the decomposition performs at certain level of driving factors i.e. temperature and soil moisture, making up a new synthesized carbon. Yet, in this model the effect of these two factors are not implemented to simplify the processes.

Organic matter formation in the soil is obtained from mass balance approach, which is simply the difference between total carbon inputs and outputs. To simplify the processes, model allows for only leaf drops as the input component, and organic matter decomposition as the output component. The first-order differential equation model to estimate soil carbon formation at time $t$ is formulated as below:

$$
\frac{d C(t)}{d t}=h_{i} I_{c}-k_{i} C_{(t)}
$$

with:

$\mathrm{C}=$ SOC formation at the top soil

$\mathrm{h}_{\mathrm{i}}=$ carbon storage coefficient [-], from $0-1$.

$I_{c}=$ total litter derived carbon inputs $\left[\mathrm{kg}_{\mathrm{c}} \mathrm{ha}^{-1} \cdot \mathrm{day}^{-1}\right]$

$\mathrm{k}_{\mathrm{i}}=$ decomposition rate constant of organic carbon [day ${ }^{-1}$ ]

The first term on the right hand-side describes the sequestration rate of top SOC. It is assumed that only part of organic carbon materials will be sequestered, while the remaining is chemically stabilized by the process of humification which is varied to their chemical composition. This model implements $h_{i}$ to describe the extent of sequestered carbon from total fresh litter entered in the soil. The $h_{i}$ parameter is carbon storage coefficient similar to humification or carbon sequestration constant concept for different models (Kemanian \& Stöckle, 2010; TaghizadehToosi et al., 2014).

The second term on the right hand-side expresses the rate of organic carbon decomposition. Model assumes that the only carbon loss during the dynamic processes in the soil is through microbial respiration following organic matter break-down. A single pool organic carbon fraction is assumed to provide a simple model. Therefore, the decomposition rate constant of organic matter expresses the averaged values among different organic carbon fractions.

Model only accounts for plant derived litter as source of carbon input, i.e. leaf litter $\left(I_{c}\right)$. The potential carbon inputs through annual application of manure or compost, and via rhizodeposition (Baptist et al., 2015) were not included due to their contribution to short-term carbon formation may be negligible. Leaf litter contribution to soil organic matter is estimated around $1.50 \%$ (Novara et al., 2015). 
The fitting parameter $h i$ is validated through the datasets obtained from field observation. The initial condition was set to zero to evaluate the potential total amount of carbon inputs through the observation periods. The optimized model is run to predict the cumulative carbon formation in each cropping system.

\section{Model validation}

To evaluate the performance of the model the efficiency (EF) is calculated (Smith et al., 1996):

$$
\begin{aligned}
& \qquad E F=\frac{\sum_{i=1}^{n}\left(O_{i}-\bar{O}\right)^{2}-\sum_{i=1}^{n}\left(P_{i}-O_{i}\right)^{2}}{\sum_{i=1}^{n}\left(O_{i}-\bar{O}\right)^{2}} \\
& \text { with: } \\
& \mathrm{O}_{\mathrm{i}}=\text { the observed values } \\
& \mathrm{P}_{\mathrm{i}}=\text { the predicted values } \\
& \bar{O}=\text { mean of observed data }
\end{aligned}
$$

The EF is calculated by comparing the variance of predicted from observed values to the variance of observed values from the mean of the observations. If the predicted values exactly match the measured values, then the EF reach the maximum value at 1 but otherwise if less than 0 the simulated values are worse.

\section{RESULTS AND DISCUSSIONS}

\section{Effect of Cropping Systems to Microclimate Condition}

Analysis of variance demonstrates that no interaction effect occurred between cropping system and observation period for air temperature, light intensity, and soil temperature (Table 1), whereas both factor's individual effect to climate variables is quite clear except for cropping system effect to soil temperature. A further post-hoc test has revealed a detailed different cropping system's type effect to each variable (Table 2). A slightly warmer condition in CoL, compared to Coff and CoP, may indicate the crop composition effect. The lowest air temperature with concomitant significantly higher relative humidity measured in CoP may be attributable to a better shade condition created by oil palm mixing crop. Conversely, the Lux meter measurement in this plot exhibited the other way around as light intensity was significantly higher.

As field records confirm the oil palm prunning taking place at $7^{\text {th }}$ day of our observation, therefore it is suggested that there was a strong increase

Table 1. Summary of analysis of variance and F test between cropping system (CS) and observation day (OD)

\begin{tabular}{lrccc}
\hline & Air temperature & Humidity & Light intensity & Soil temperature \\
\hline CS & $1.67 \times 10^{-5} * * *$ & $<2.00 \times 10^{-16} * * *$ & $3.70 \times 10^{-3} * *$ & 0.39 \\
OD & $<2.00 \times 10^{-16} * * *$ & $<2.00 \times 10^{-16} * * *$ & $1.21 \times 10^{-4} * * *$ & $5.87 \times 10^{-3} * *$ \\
CSxOD & 0.90 & $7.17 \times 10^{-12} * * *$ & 0.662 & 1.00 \\
\hline
\end{tabular}

Notes: $\quad * * \pm$ Sig. at $\alpha=0.01 ; * * * \pm$ Sig. at $\alpha=0.001$

Table 2. Cropping system effect to microclimate conditions

\begin{tabular}{lcccc}
\hline \multirow{2}{*}{ Crop system } & $\begin{array}{c}\text { Air temperature } \\
\left({ }^{\circ} \mathrm{C}\right)\end{array}$ & $\begin{array}{c}\text { Humidity } \\
(\%)\end{array}$ & $\begin{array}{c}\text { Light intensity } \\
(\text { Lux })\end{array}$ & $\begin{array}{c}\text { Soil temperature } \\
\left({ }^{\circ} \mathrm{C}\right)\end{array}$ \\
\hline Coff & $27.51^{\mathrm{b}}$ & $75.91^{\mathrm{a}}$ & $2477.55^{\mathrm{b}}$ & $25.35^{\mathrm{a}}$ \\
$\mathrm{CoL}$ & $27.68^{\mathrm{a}}$ & $74.19^{\mathrm{b}}$ & $2653.79^{\mathrm{b}}$ & $25.32^{\mathrm{a}}$ \\
$\mathrm{CoP}$ & $27.39^{\mathrm{b}}$ & $72.55^{\mathrm{c}}$ & $3131.26^{\mathrm{a}}$ & $25.07^{\mathrm{a}}$ \\
\hline Notes: & Numbers in the same column followed by the same letter are not significantly different at $\alpha=0.05 .($ Coff $=$ coffee- \\
& lamtoro, CoL = cocoa-lamtoro, CoP = cocoa-oilpalm).
\end{tabular}


in light intensity for the last one week (Figure 2, light intensity). Yet, the increase in light intensity did not affect the temperature and humidity in the canopy area. The absence of positive correlation among light intensity, and temperature and relative humidity in this investigation, however, has confirmed a previous report (Yue et al., 2018). Soil temperature measurements showed an insignificant difference effect of various cropping system. Additionally, their values are consistently lower than the same measurement in the air, indicating a better soil effect to hold the heat than air does.

Diurnal dynamics of climate variables (Figure 2) are normal phenomena resulting from the strong interplay among various climate components. Statistical evaluations of measurement from averaged different cropping systems demonstrate a significant fluctuations from day to day (data not presented). Since the averaged value of plots among different cropping system is less important than the individual plot, therefore the analysis of variance results for observation day (Table 1) will not be discussed in this paper.

The daily variation designated by the error bars indicate their largest for light intensity
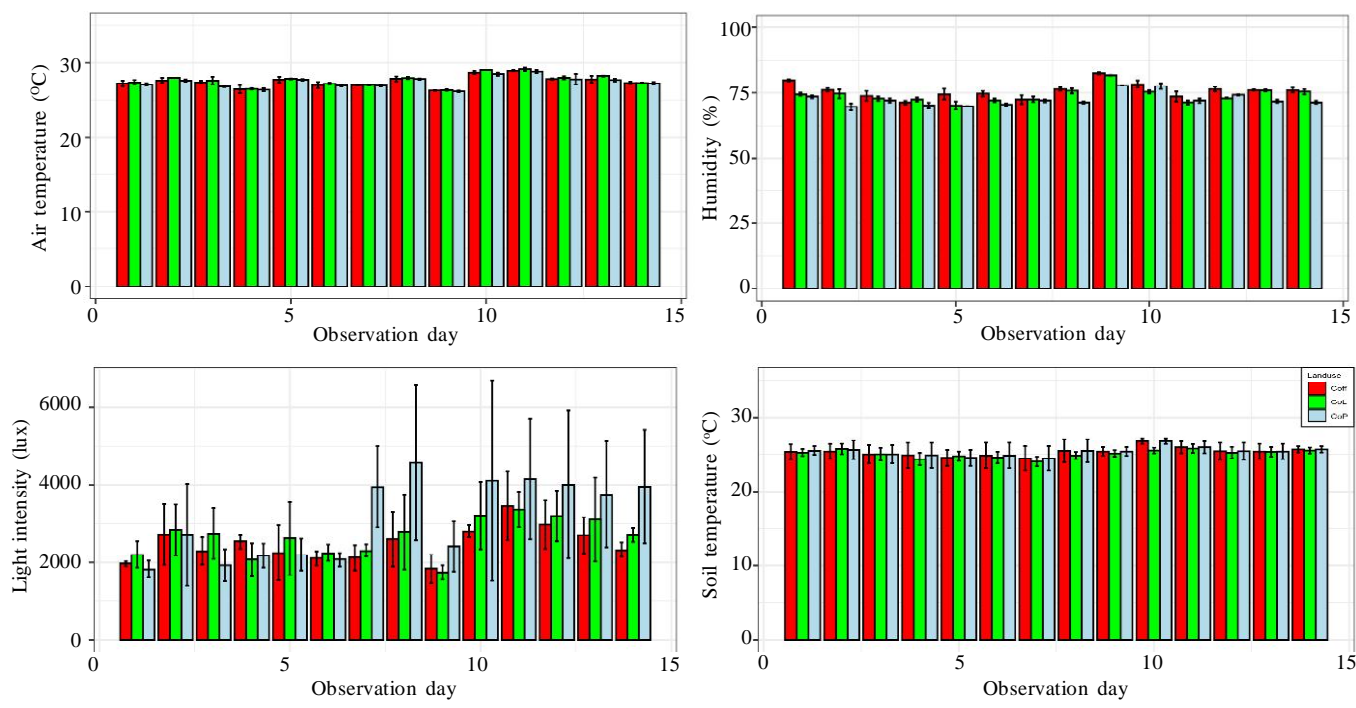

Figure 2. Microclimate variables, i.e. air temperature, humidity, light intensity, and soil temperature as a response to different cropping systems. Error bars indicate a standard deviation from single day measurements $(\mathrm{Coff}=$ coffee-lamtoro, $\mathrm{CoL}=$ cocoa-lamtoro, $\mathrm{CoP}=$ cocoa-oilpalm $)$. 
the relative homogeneity of under canopy microclimate condition. The difference level of measurement, i.e. 0 and $100 \mathrm{~cm}$ distance from the ground, provide the same absolute values for the two variables. The normal variation was occured from morning to midday, and to evening 's observation during the day (data not presented).

\section{Effect of Cropping Systems to Soil and Crop Characteristics}

Due to a similarity of soil and climate type in the plot of study, any change related to spatial distribution of soil physical characteristics may be as a response of the intensity of cropping systems. This is because a typical positive correlation between organic carbon input, as results of different cropping systems such as amount and quality of litter, and agronomical practices related inputs, i.e. manure, mineral fertilizer, compost etc, and soil physical characteristics.

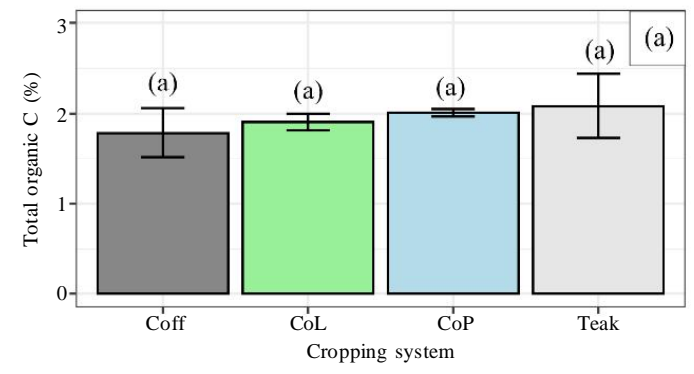

Typical soil characteristics between the plots has been evidenced through $\mathrm{BD}$ measurement with range of values of 1.02$1.14 \mathrm{~g} / \mathrm{cm}^{3}$ in Coff, $0.98-1.21 \mathrm{~g} / \mathrm{cm}^{3}$ in $\mathrm{CoL}$, and $1.02-1.18 \mathrm{~g} / \mathrm{cm}^{3}$ in CoP. As BD is not only affected by the mineral composition of soils, but also by the organic fractions therefore the similar range of their values may also be interpretable the similar current level of organic carbon in the soil.

Additionally, soil moisture content is insignificantly higher in CoL compared to different plots, which is almost up to $40 \%$ (Figure 3b). Yet, the error bars generated in the plot suggest a considerable high level of variability in this site, similar to Coff and Teak plots. Conversely, it also demonstrates a high homogeneity of soil characteristics in CoP plot with standard deviation around $1.50 \%$. With error bar level similar to SOC, a close-dependent each other may be occurred (Figure 3a).

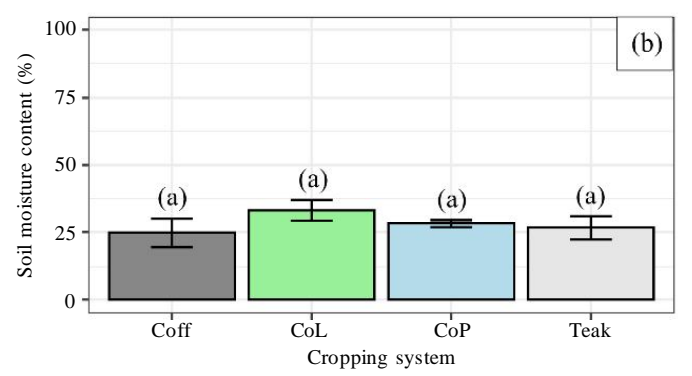

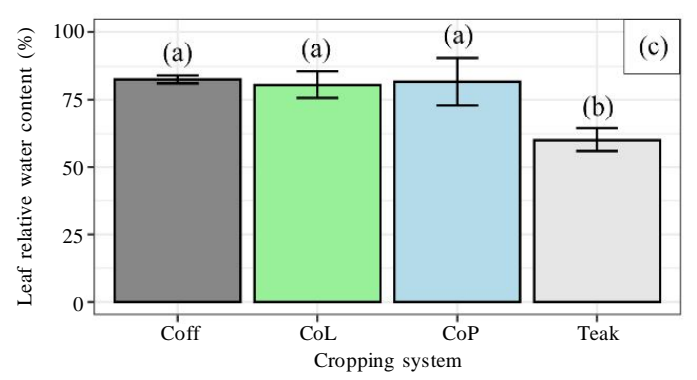

Figure 3. Post-hoc test of SOC, soil moisture, leaf RWC, under different cropping systems, i.e. (a) coffeelamtoro, Coff (b) cocoa-lamtoro, CoL (c) cocoa-oilpalm, CoP, and teak. The dots represent the average values with standard deviations. Treatments with different letters and colours are significantly different 
Relative water contents are significantly higher in Coff, CoL, and CoP than in Teak plot (Figure 3c). Given the similar level of soil moisture (Figure 3b), the lower RWC in Teak plot may have indicated a higher transpiration rate. Additionally, RWC reduced for Teak's leaves down to ca. $60 \%$ may be attributable to severe drought stress (Galeano et al., 2019). The drought condition in the field was confirmed, on which the study was carried out, since very low rainfall evidence ( $<10 \mathrm{~mm}$ ) was recorded during July 2019 (Figure 1). The higher RWC for other plots at ca. $80 \%$ could be interpretable a better water balance condition between microenvironment, especially soil, and crop, i.e. leaf tissue. In this case, a shade crop types, i.e. Leucaena sp., and oil palm may show an important role in maintaining water balance in soil-plant systems.

\section{Cropping Systems and Microclimate Effects}

Post-hoc test results suggest an insignificant difference of amount of SOC in different plots (Figure 4a). As the two identified SOC source in the field are litter derived organic carbon, and agricultural practices such as instance manuring, and composting, therefore SOC variations across the plots is highly likely related to the dynamics interplay between these two factors. Despite their insignificant difference, the higher amount of SOC in natural Teak plot may have obviously resulted from the higher litter input as a regular annual $20 \mathrm{~L}$ per tree compost inputs are applied for Coff, CoL, and CoP plots.

The importance of leaf litter derived carbon especially where no special shade crops are available such as in Teak plot. In different plots, the contribution of carbon from shade crops may be expected. The biomass input from Leucaena sp. shade crop generally can be up to ca. $0.48 \mathrm{~kg}$ C.ha.day ${ }^{1}$ (Baon \& Wibawa, 2005), while for oil palm is a bit higher of up to ca. $3.64 \mathrm{~kg} \mathrm{C}$.ha.day $^{-1}$ (Lamade \& Bouillet, 2005). The high difference of litter derived carbon from the two crops may not be effected into the soil as SOC stock estimation revealed a no important difference. Data calculation for SOC stock

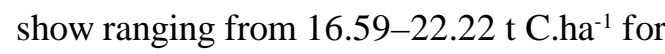
Coff, 19.21-22.36 t C.ha- ${ }^{-1}$ for CoL, 20.5323.68 t C.ha ${ }^{-1}$ CoP, and 18.98-26.84 t C.ha ${ }^{-1}$ for Teak plots. Data show a similar value obtained from $\mathrm{CoL}$ and $\mathrm{CoP}$ implying a no considerable shade crop effects to SOC stocks. The highest SOC stock is recorded under Teak plot but with high variability between sampling point.

Statistical analysis demonstrates a significant difference effect of cropping systems to air temperature, relative humidity, and light intensity (Table 2). As the observation plots are located at the same topographical condition, therefore a landform related climate variation is likely negligible. Therefore, as already stated in the earlier discussions that these under canopy microclimate variations may be attributable to shade condition resulting from differing in crop compositions. Instead, regular agronomical practices such as pruning may have determined more the short-term microclimate fluctuations (Figure 2).

Among microclimate parameters observed in this study, both air and soil temperature may play a crucial role in determining the level of soil organic carbon, as their strong connection has been recognized (Paul, 2016). As the difference in both air and soil temperature among cropping systems may be too small (Table 2), since microbial metabolic transformation has to do with temperature of which its rate will increase doubled with the increase in $10^{\circ} \mathrm{C}$ in a specific range, which is often defined as $\mathrm{Q}_{10}$ constant (Davidson et al., 2012), therefore a less than $1^{\circ} \mathrm{C}$ difference 
with respect to both air and soil temperature among different crop systems (Table 2) may not really influence the rate of short-term soil organic carbon formation.

\section{Soil Carbon Formation Model}

A simple model is developed to improve the understanding of soil carbon formation under different cropping systems. As model assumes plant litter as the only source of carbon inputs, therefore the role of main crops, i.e. cocoa or coffee, as well as shade crop, i.e. Leucaena sp., to soil organic carbon development is evaluated. This allows a direct comparison's effect between two main crops, i.e. coffee and cocoa, since the same shade crop types used in these plots. To do so, two observation data collected from Coff and CoL plots were used to validate the model.

The optimized model shows a high efficiency (EF) for CoL but low for Coff (Table 3). This means that the model predicts the carbon formation in Coff with lower accuracy. In this plot, the high amount of litter derived carbon input in a short of period giving rise to an asymptotic curve type may not be well defined through the model. Soil process included in the model development, i.e. soil storage capacity $\left(h_{i}\right)$, is able to explain the formation of soil carbon in both plots. The fitting of model has ended up with $h_{i}$ values 0.017 and 0.014 for both Coff and CoL. With higher $h_{i}$ values, Coff cropping system provide a potential to sequester more SOC than $\mathrm{CoL}$ (Figure 5a). Since the soil type is similar, the higher potential SOC sequestration in this plot may be attributable to the higher total litter derived carbon (Table 3). With total carbon inputs 4.14 kg.ha.day ${ }^{1}$, SOC formed in this cropping system is estimated of up to 0.60 kg.ha.day ${ }^{-1}$ within just 10 days (Figure 5a), which is $50 \%$ higher than the carbon produced in CoL for the same period. Additionally, the difference in terms of tissue quality as indicated by leaf carbon, i.e. $40.31 \%$ for Coff and $33.33 \%$ for CoL, may also contribute to the higher carbon inputs in Coff.

In this model, the decomposition rate of soil organic carbon, $k$, is assumed to be the same. As it is always related to its chemical composition (Manzoni et al., 2012), therefore the lower decomposition rate of organic carbon is associated with the dominant of slowly decomposable organic fractions. Former report demonstrated the presence of some slowly decomposed organic carbon fractions such as cellulose-hemicellulose, polyphenol, and lignin in coffee and cocoa residues (Moco et al., 2010; Pujol et al., 2013), therefore typical $k$ value $0.003-0.08$ day $^{-1}$ may be expected (Paul, 2016). A faster decomposition rate of easily decomposable organic carbon, such as sugar-amino acids with $k$ value 0.20 day $^{-1}$ (Voroney et al., 1981), may be important especially for short-term organic carbon dynamics. Yet, in terms of soil organic

Table 3. Model variable, parameter, and efficiency applied for SOC simulation $(\mathrm{Coff}=$ coffee-lamtoro, $\mathrm{CoL}=$ cocoa-lamtoro)

\begin{tabular}{|c|c|c|c|c|c|}
\hline & Symbol & Unit & Coff & $\mathrm{CoL}$ & Source of data \\
\hline Carbon input & Ic & & & & \\
\hline Coffee & & kg C.ha ${ }^{-1} \cdot$ day $^{-1}$ & 3.65 & & Field measurement \\
\hline Leucaena sp. & & kg C.ha ${ }^{-1} \cdot$ day $^{-1}$ & 0.48 & & Baon \& Wibawa (2005) \\
\hline Total & & kg C.ha ${ }^{-1} \cdot$ day $^{-1}$ & 4.14 & & \\
\hline Cocoa & & kg C.ha ${ }^{-1} \cdot$ day $^{-1}$ & & 2.14 & Field measurement \\
\hline Leucaena sp. & & kg C.ha ${ }^{-1} \cdot$ day $^{-1}$ & & 0.48 & Baon \& Wibawa (2005) \\
\hline Total & & kg C.ha ${ }^{-1} \cdot$ day $^{-1}$ & & 2.62 & \\
\hline Carbon storage coefficient & $h_{i}$ & - & 0.017 & 0.014 & Fitting data \\
\hline Decomposition rate of $\mathrm{OC}$ & $k_{i}^{l}$ & kg C.ha ${ }^{-1} \cdot$ day $^{-1}$ & 0.01 & 0.01 & Estimation \\
\hline Model validation & $\mathrm{EF}$ & - & 0.58 & 0.93 & Calculation \\
\hline
\end{tabular}


carbon sequestration, this fraction may be negligible. For modelling study, slow decomposable organic carbon fractions, with assumed constant value $k 0.01$, will be taken into account since it may play an important role in soil organic carbon sequestration.

Expressing the model formulated into plots (Figure 4a and b), may have demonstrated a different type of curve produced with different cropping system. Model extrapolation (not presented) revealed that during the first month of leaf litter addition, the line curve produced in Coff's plot is a bit steeper than CoL plot. As discussed before, in this period the organic carbon formation is faster in the first plot as a result of the higher $\mathrm{C}$ storage coefficient (hi) (Table 3).

The generated asymptotic curve types from long-run model simulation may have confirmed a non-responsive effect of higher potential of oilpalm as a shade crop in $\mathrm{CoP}$ to the increase in soil organic carbon formation than Leucaena sp. both in Coff and CoL, as discussed in the previous section. This means that the continuous addition of litter derived carbon is not necessarily linearly increasing the
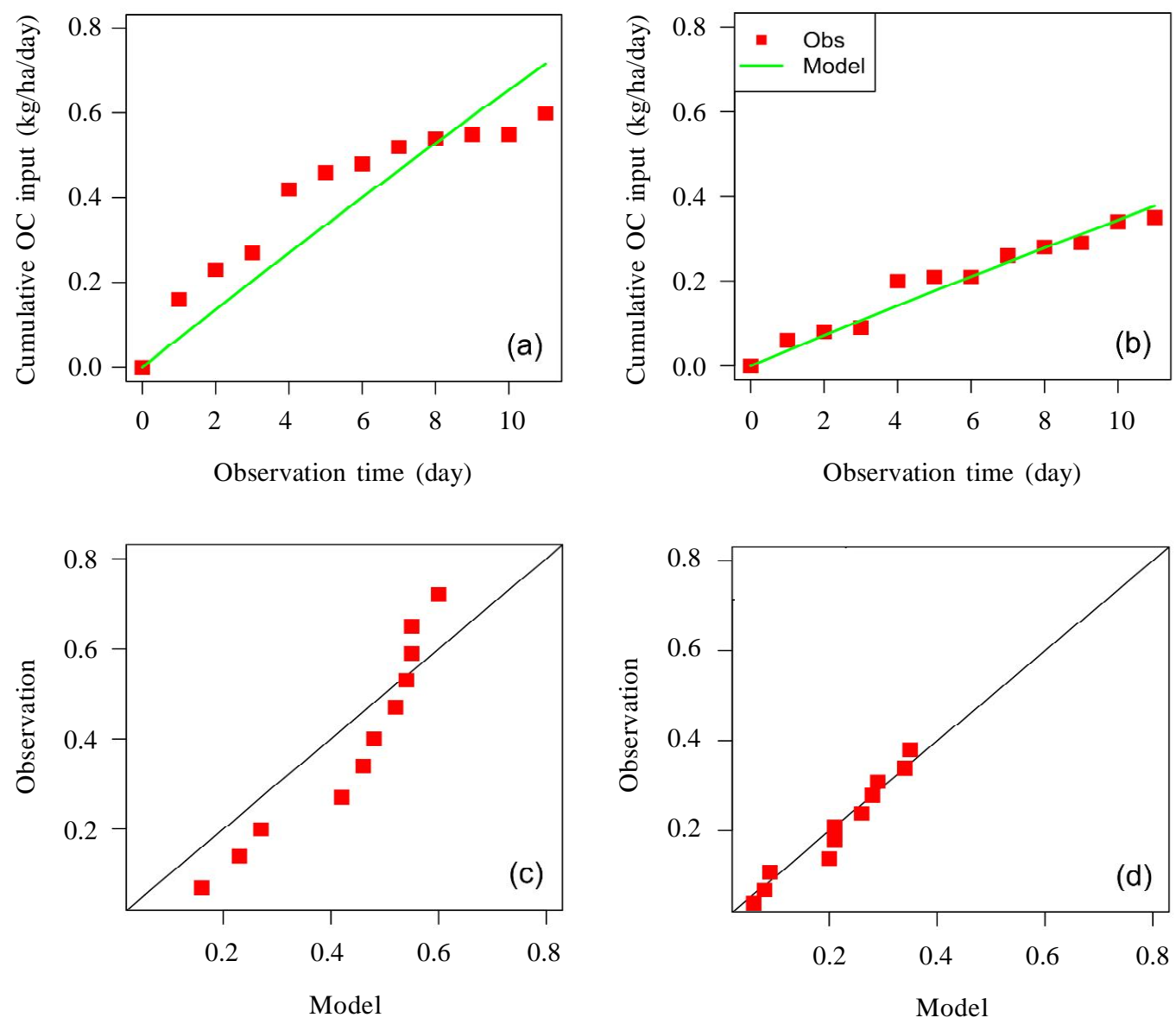

Figure 4. Litter derived soil carbon development, a and b) fitting model to determine the storage coefficient parameter, hi, for coffee-Leucaena sp. (Coff), and cocoa-Leucaena sp. (CoL), c and d) model validation providing a different viewpoint from the EF formula (Smith et al., 1996), as presented in Table 3. 
SOC formation yet there is a deflection point at which the curve will turn into plateau to confirm the upper limit of carbon storage. This phenomenon may indicate a similarity to a concept "carbon saturation" (Campbell \& Paustian, 2015), where carbon storing capacity is likely soil type dependent. In this simulation, the effect of soil type to the formation of SOC is unable to confirm due to the limited of observation area. An extended study to evaluate the effect of different soil types to soil carbon formation in different cropping systems may potentially useful to improve the knowledge of how does carbon formation works in view of soil properties related different inherent storing capacity.

The difference of curve types produced from the simulation between Coff and Col are evidenced the different of carbon dynamics in both cropping systems. It is clear that different quantity of litter produced in both cropping systems playing a significant role in terms of soil organic carbon formation. Assuming the same level of shade crop derived litter quantity, i.e. $0.48 \mathrm{~kg} \mathrm{C.ha.day}{ }^{1}$, the higher cumulative SOC formation in Coff may have related to the higher input of main crop's litter observed during the study (Table 3).

Several factors may be responsible to the differing in carbon input level between Coff and CoL such as litter quality, plant age, and daily fluctuation of litterfall. Litter quality sample was not determined in the present study therefore it was assumed that both Coff and CoL derived litter posing similar chemical composition with averaged coefficient $k$ value 0.01 day $^{-1}$ (Table 3), discussed in the previous section. A differing in plant age may also determine the level of biomass produced. With higher potential biomass, as corresponding to earlier planting time, however, may associate with higher amount of carbon input in Coff. Additionally, the field observation duration may also suggest the potential different litterfall quantity in different time interval. Therefore, present study is likely limited to dry season condition since different microclimate condition may result in different litterfall quantity.

\section{CONCLUSIONS}

The presence of cropping system effect, i.e. shading condition and agronomical practices, to microclimate variation was evidenced. These two factors have significantly affected air temperature, humidity, and light intensity variation except for soil temperature. Conversely, the effects to soil moisture content, amount of carbon, and RWC were not obvious. Model simulation revealed a cropping system related typical curve pattern. A steeper curve expressed in Coff plot, with concomitant higher carbon storage coefficient $h i 0.017$ versus 0.014 in CoL, has indicated a faster SOC formation. Additionally, it suggests a crucial role of amount and quality of litter derived carbon fractions to determine the dynamics of soil carbon. Assuming the similarity of litter quality, the higher cumulative organic carbon produced in Coff is related to the higher quantity of litterfall. In this study, a litter dependent of SOC formation level was clearly simulated by reduced the amount of input. Furthermore, the capacity of soil to store additional organic carbon inputs may be limited. The analysis indicates the presence of maximum point of storage capacity for carbon, giving rise to the limitation of SOC addition's effect to soil. The model fits better for CoL than Coff as indicated by their EF values, i.e. 0.93 and 0.58 .

\section{ACKNOWLEDGEMENTS}

We would like to thank Anggun Prasetyo and Lia Christyaningrum for their fieldworks and data collection prepared for this paper. 


\section{REFERENCES}

Baon, J.B. \& A. Wibawa (2005). Organic matter and soil moisture content and coffee production in double cropping with organic matter source plants. Pelita Perkebunan, 21, 43-54.

Baptist, F.; I. Aranjuelo; N. Legay; L. LopezSangil; G. Molero; P. Rovira \& S. Nogués (2015). Rhizodeposition of organic carbon by plants with contrasting traits for resource acquisition: responses to different fertility regimes. Plant Soil, 394, 391-406.

Beerling, D.J. \& W.G. Chaloner (1992). Stomatal density as an indicator of atmosphereic $\mathrm{CO}_{2}$ concentration. The Holocene, 2 , 71-78.

Campbell, E.E. \& K. Paustian (2015). Current developments in soil organic matter modelling and the expansion of model applications: a review. Environmental Research Letter, 10, 1-36.

Cao, J.; X. He; Y. Chen; Y. Chen; Y. Zhang; S. Yu; L. Zhou; Z. Liu; C. Zhang \& S. Fu (2020). Leaf litter contributes more to soil organic carbon than fine roots in two 10-year-old subtropical plantations. Science of the Total Environment, 704. (in press).

Chen, Y.; J. Cao; X. He; T. Liu; Y. Shao; C. Zhang; Q. Zhou; F. Li; P. Mao; L. Tao; Z. Liu; Y. Lin; L. Zhou; W. Zhang \& S. Fu (2020). Plant leaf litter plays a more important role than roots in maintaining earthworm communities in subtropical plantations. Soil Biology and Biochemistry, 144. (In press).

Córdova, S.C.; D.C. Olk; R.N. Dietzel; K.E. Mueller; S.V. Archountouilis; M.J. Castellano (2018). Plant litter quality affects the accumulation rate, composition, and stability of mineral-associated soil organic matter. Soil Biology and Biochemistry, $125,115-124$.

Davidson, E.A.; S. Samanta, S.S. Caramori \& K. Savage (2012). The Dual Arrhenius and Michaelis-Menten kinetics model for decomposition of soil organic matter at hourly to seasonal time scales. Global Change Biology, 18, 371-384.

Ehrenbergerová, L.; E. Cienciala, A. Kuèera, L. Guy \& H. Habrová (2016). Carbon stock in agroforestry coffee plantations with different shade trees in Villa Rica, Peru. Agroforesty System, 90, 433-445.

Erwiyono, R.; A.A. Prawoto \& A.S. Murdiyati (2012). Nutrient resorption efficiency of cocoa plants on lowland of Alluvial plain. Pelita Perkebunan, 28, 32-44.

Evizal, R.; Tohari, I.D. Prijambada; J. Widada \& D. Widianto (2009). Ecosytem service of shade trees on nutrient cycling and productivity of coffee agro-ecosystems. Pelita Perkebunan, 25, 23-27.

Franks, P.J.; T.W. Doheny-Adams; Z.J. BrittonHarper \& J.E. Gray (2015). Increasing water-use efficiency directly through genetic manipulation of stomatal density. New Phytologist, 207, 188-195.

Galeano, E.; T.S. Vasconcelos; P.N. de Oliveira \& H. Carrer (2019). Physiological and molecular responses to drought stress in teak (Tectona grandis L.f.). PLoS ONE, 14, 1-26.

Hetherington, A.M \& F.I. Woodward (2003). The role of stomata in sensing and driving environmental change. Nature, 424, 901-908.

Hughes, J.; C. Hepworth; C. Dutton,; J.A. Dunn; L. Hunt; J. Stephens; R. Waugh; D.D. Cameron \& J.E. Gray (2017). Reducing stomatal density in barley improves drought tolerance without impacting on yield. Plant Physiology, 174, 776-787.

Kemanian, A.R. \& C.O. Stöckle (2010). C-Farm: A simple model to evaluate the carbon balance of soil profiles. Europian Journal Agronomy, 32, 22-29.

Kögel-Knabner, I. (2017). The macromolecular organic composition of plant and microbial residues as inputs to soil organic matter: Fourteen years on. Soil Biology and Biochemistry, 105, A3-A8.

Lal, R. (2011). Sequestering carbon in soils of agroecosystems. Food Policy, 36, 533-539. 
Lamade, E. \& J-P. Bouillet (2005). Carbon storage and global change: the role of oil palm. OCL, 12, 154-160.

Manzoni, S.; G. Pineiro; R.B. Jackson; E.G. Jobbágy; J.H. Kim \& A. Porporato (2012). Analytical models of soil and litter decomposition: Solutions for mass loss and timedependent decay rates. Soil Biology and Biochemistry, 50, 66-76.

Moço, M.K.S.; E.F. Gama-Rodrigues; A.C. GamaRodrigues; R.C.R. Machado \& V.C. Baligar (2010). Relationships between invertebrate communities, litter quality and soil attributes under different cacao agroforestry systems in the south of Bahia, Brazil. Applied Soil Ecology, 46, 347-354.

Monroe, P.H.M.; E.F. Gama-Rodrigues, A.C. GammaRodrigues \& J.R.B. Marques (2016). Soil carbon stocks and origin under different cacao agroforestry systems in Southern Bahia, Brazil. Agriculture, Ecosystems and Environment, 221, 99-108.

Novara, A.; J. Rühl; T. La Mantia; L. Gristina; S. La Bella \& T. Tuttolomondo (2015). Litter contribution to soil organic carbon in the processes of agriculture abandon. Soil Earth, 6, 425-432.

Paul, E.A. (2016). The nature and dynamics of soil organic matter: Plant inputs, microbial transformations, and organic matter stabilization. Soil Biology and Biochemistry, 98, 109-126.

Prastowo, E.; L.D. Agustina \& C. Prayogo (2020). Earthworm abundance and soil characteristics following cocoa waste and manure applications. Pelita Perkebunan, $36,47-55$.

Prastowo, E.; N.P. Erdiansyah \& R. Arimarsetiowati (2019). Leaf mineral composition of coffee infected by a Hemileia vastatrix fungus in Bondowoso, East Java. Pelita Perkebunan, 35, 12-21.
Pujol, D.; C. Liu; J. Gominho; M.A. Olivella; N. Fiol; I. Villaescusa \& H. Pereira (2013). The chemical composition of exhausted coffee waste. Industrial Crop and Products, 50, 423-429.

Rumpel, C. \& I. Kögel-Knabner (2011). Deep soil organic matter - a key but poorly understood component of terrestrial C cycle. Plant Soil, 338, 143-158.

Smith, J.U.; P. Smith \& T.M. Addiscott (1996). Quantitative methods to evaluate and compare soil organic matter (SOM) models. p. 181-201. In: Evaluation of Soil Organic Matter Models. (D.S. Powlson; P. Smith \& J.U. Smith, Eds). Springer. Rothamsted, UK.

Taghizadeh-Toosi, A.; B.T. Christensen; N.J. Hutchings; J. Vejlin; T. Kätterer; M. Glending; J.E. Olesen (2014). CTOOL: A simple model for simulating whole-profile carbon storage in temperate agricultural soils. Ecological Modelling, 292, 11-25.

Voroney, R.P.; J.A. van Veen \& E.A. Paul (1981). Organic $\mathrm{C}$ dynamics in grassland soils. 2. Model validation and simulation of the long-term effects of cultivation and rainfall erosion. Canadian Journal of Soil Science, 61, 211-224.

Xu, Z.; Y. Jiang, B. Jia \& G. Zhou (2016). Elevated-CO $\mathrm{CO}_{2}$ response of stomata and its dependence on environmental factors. Frontiers in Plant Science, 7, 1-15.

Yue, W.; S. Shu-chai; L. Ma; Y. Shao-yan; W. Yuwei; W. Xiang-nan (2018). Effects of canopy microclimate on fruit yield and quality of Camellia oleifera. Scientia Horticulturae, 235, 132-141.

Yulianti, T.; S. Abdoellah; D. Suprayogo \& N.P. Sari (2018). Cocoa production as affected by shade tree species and soil quality. Pelita Perkebunan, 34, 80-89.

$$
* * 0 * *
$$

